\title{
Electrochemical Determination of Citalopram by Adsorptive Stripping Voltammetry-Determination in Pharmaceutical Products
}

\author{
Henri P. A. Nouws, Cristina Delerue-Matos and Aquiles A. Barros
}

\begin{abstract}
The electrochemical behavior of citalopram was studied by square-wave and square-wave adsorptive-stripping voltammetry (SWAdSV). Citalopram can be reduced and accumulated at a mercury drop electrode, with a maximum peak current intensity being obtained at a potential of approximately $-1.25 \mathrm{~V}$ vs. $\mathrm{AgCl} / \mathrm{Ag}$, in an aqueous electrolyte solution of $\mathrm{pH}$ 12. A SWAdSV method has been developed for the determination of citalopram in pharmaceutical preparations. The method shows a linear range between $1.0 \times 10^{-7}$ and $2.0 \times 10^{-6} \mathrm{~mol} \mathrm{~L}^{-1}$ with a limit of detection of 5 $\times 10^{-8} \mathrm{~mol} \mathrm{~L}^{-1}$ for an accumulation time of $30 \mathrm{~s}$. The precision of the method was evaluated by assessing the repeatability and intermediate precision, achieving good relative standard deviations in all cases $(\leq 2.3 \%)$. The proposed method was applied to the determination of citalopram in five pharmaceutical products and the results obtained are in good agreement with the labeled values.
\end{abstract}

Keywords: Citalopram, SSRI, hanging mercury drop electrode, adsorptive-stripping voltammetry, pharmaceutical analysis 


\section{INTRODUCTION}

Citalopram (CTL) (Figure 1), a selective serotonin re-uptake inhibitor (SSRI) developed by H. Lundbeck A/S (Denmark), is indicated for the symptomatic relief of depressive illness.

For drug development and for treatment purposes it is very important to be able to quantify the drug and its metabolites in a wide variety of samples (serum, plasma, urine, and pharmaceutical products) to establish its pharmacokinetics, metabolic pathway, dosage, etc. This implies the need for analytical methods with high sample-throughput, low limits of detection, and low maintenance costs.

Usually CTL and its metabolites are analyzed using high performance liquid chromatography (HPLC) coupled with spectrometric detectors, ultraviolet/diode array (Skibinski and Misztal 2005; Frahnert et al. 2003; Duverneuil et al. 2003; Berzas et al. 2002; Tournel et al. 2001), mass spectrometric (Pistos et al. 2004; Gutteck and Rentsch 2003; Kollroser and Schober 2003), and fluorimetric (Meng and Gauthier 2005; Raggi et al. 2003; Waschgler et al. 2002; Macek et al. 2001; Lacassie et al. 2000). This widespread usage of HPLC methods is justified by the high sensitivity and the low limit of detection usually obtained and the possibility of simultaneous analysis of the drug and its metabolites increases its use even further. The main disadvantages of HPLC are the relatively long analysis times and high acquisition and maintenance costs. Several other methods, based on electrophoresis (Flores et al. 2004; Andersen et al. 2003; Mandrioli et al. 2003), micellar electrokinetic capillary chromatography (Labat et al. 2002; Pedersen-Bjergaard and Halvorsen 2000), isotachophoresis (Buzinkaiova and Polonsky 2000), gas chromatography (Berzas et al. 2004; Martinez et al. 2004; Lacassie et al. 2000; Eap et al. 1998), thin layer chromatography (Misztal and Skibinski 2001), and UV spectrophotometry (Sagar 2004), have also been described. No official quantification methods are reported in the

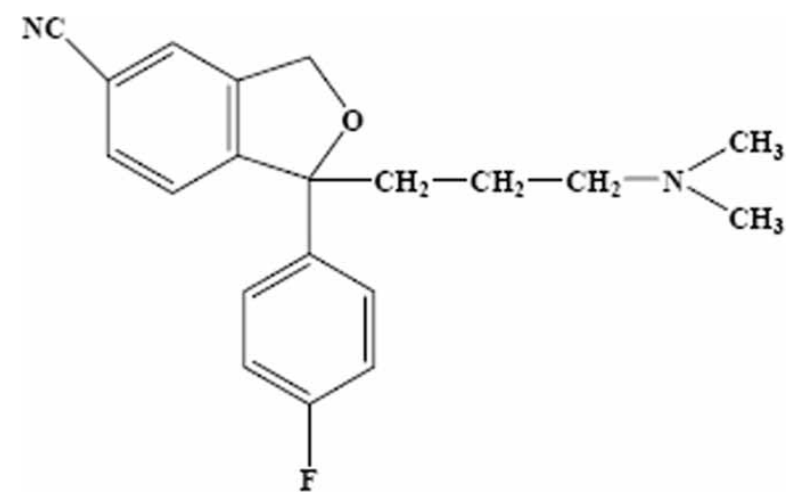

Figure 1. Chemical structure of citalopram. 
various available pharmacopoeias. Until now no electrochemical studies on the determination of CTL have been reported.

Adsorptive-stripping voltammetry (AdSV) is a technique mainly used for the analysis of organic compounds, which can be accumulated at, for example, the hanging mercury drop electrode (HMDE) surface and afterwards stripped off by applying a potential scan (Wang 1985). The introduction of highscan-rate voltammetric techniques, for example square-wave voltammetry (SWV), increases the sensitivity of AdSV even further (Barros et al. 1999).

The present paper shows that CTL exhibits adsorption onto the mercury electrode surface. By using this phenomenon and by accumulation of the compound at the HMDE prior to a square-wave voltammetric scan, a high sensitivity can be achieved in its determination. The effect of several experimental parameters on the analytical signal of CTL was evaluated in order to develop a square-wave adsorptive-stripping voltammetric (SWAdSV) method for its determination in pharmaceutical products. The proposed method was successfully applied to the quantification of CTL, in the presence of excipients, in five commercial pharmaceutical products.

\section{EXPERIMENTAL}

\section{Apparatus}

Voltammetric measurements, using SWV and SWAdSV, were performed using an Autolab PGSTAT12 (Metrohm-EcoChemie) potentiostat, controlled by a PC by use of GPES 4.9 software from Metrohm-EcoChemie, and a Metrohm 663 VA stand containing a three-electrode cell (all Metrohm). This voltammetric cell consisted of a multimode mercury working electrode, used in the static mercury-drop position (SMDE), an $\mathrm{Ag} / \mathrm{AgCl} /$ $\mathrm{KCl} 3 \mathrm{~mol} \mathrm{~L}^{-1}$ reference electrode, and a glassy carbon auxiliary electrode.

\section{Reagents and Solutions}

A CTL hydrobromide standard was kindly provided by $\mathrm{H}$. Lundbeck A/S (Denmark) and used without further purification. Stock solutions of CTL were prepared by dissolution of precisely weighed amounts of the standard in deionized water. These stock solutions were diluted with deionized water and electrolyte solution to furnish the desired concentration. All other reagents, of p.a. quality, were purchased from Merck and Sigma-Aldrich. All solutions were prepared in deionized water (conductivity $<0.1 \mu \mathrm{S} \mathrm{cm}^{-1}$ ).

For the optimization of electrolyte $\mathrm{pH}$ several universal buffers $\left(I=0.3 \mathrm{~mol} \mathrm{~L}^{-1}\right.$ ) (Fernández and Martin 1977) between pH 1.9 and 11.6 were used. After optimization, a $\mathrm{pH} 12.0 \mathrm{NaOH}-\mathrm{KCl}$ electrolyte solution $\left(I=0.1 \mathrm{~mol} \mathrm{~L}^{-1}\right)$ was used. 


\section{Procedures}

\section{General Procedure}

To obtain the background voltammogram, a 10.00 or $15.00 \mathrm{~mL}$ volume of the supporting electrolyte was introduced in a voltammetric cell and purged with oxygen-free nitrogen for $10 \mathrm{~min}$. The required accumulation potential $\left(E_{\text {acc }}\right)$ was then applied to the electrode for a selected accumulation time $\left(t_{\text {acc }}\right)$ while the solution was stirred. Finally, stirring was stopped and a square-wave voltammogram was recorded by applying a scan in the negative direction. After recording the background voltammogram, an aliquot of the analyte (standard or sample) solution was added and the procedure was repeated.

\section{Validation Procedure}

When the optimum experimental conditions had been found, validation of the method was performed. For this purpose, the linear range, limit of detection (LOD), limit of quantification (LOQ), repeatability, and intermediate precision were evaluated (The United States Pharmacopoeia 2000).

The linear range was determined by analyzing CTL solutions in the range $1.0 \times 10^{-7}$ to $6.0 \times 10^{-6} \mathrm{~mol} \mathrm{~L}^{-1}$ for $t_{\text {acc }}$ values of 10 and $30 \mathrm{~s}$. The LOD and LOQ were calculated from the linear calibration plot (Miller and Miller 2000).

Repeatability and intermediate precision were assessed at three concentrations. CTL solutions of $6.0 \times 10^{-7}, 1.4 \times 10^{-6}$, and $2.2 \times 10^{-6} \mathrm{~mol} \mathrm{~L}^{-1}$ were used for $t_{\mathrm{acc}} 10 \mathrm{~s}$ and $6.0 \times 10^{-7}, 1.1 \times 10^{-6}$, and $1.6 \times 10^{-6} \mathrm{~mol} \mathrm{~L}^{-1}$ solutions were evaluated for $t_{\mathrm{acc}} 30 \mathrm{~s}$. To assess the repeatability, five replicate measurements of each solution were made in a short period of time. To determine intermediate precision, the solutions were each analyzed five times per day for three consecutive days.

\section{Pharmaceutical Analysis}

The pharmaceutical products used for evaluation of the adequacy of the developed method were purchased in Belgium and Spain, because CTLcontaining pharmaceuticals are not commercialized in Portugal. All these products have a labeled CTL-value of $20 \mathrm{mg}$ per tablet. For analysis, 10 tablets of each product were weighed, finely powdered, and a mass equivalent to about $10.4 \mathrm{mg}$ of CTL was dissolved in $100.0 \mathrm{~mL}$ of deionized water by sonication for $15 \mathrm{~min}$. This solution was then diluted 100 -fold with electrolyte and an adequate volume of the resulting solution was added to $15.00 \mathrm{~mL}$ of electrolyte contained in the voltammetric cell. Quantification was carried out using the standard addition method by adding increasing quantities of a CTL standard directly to the sample solution contained in the voltammetric cell. This procedure was repeated in triplicate for each 

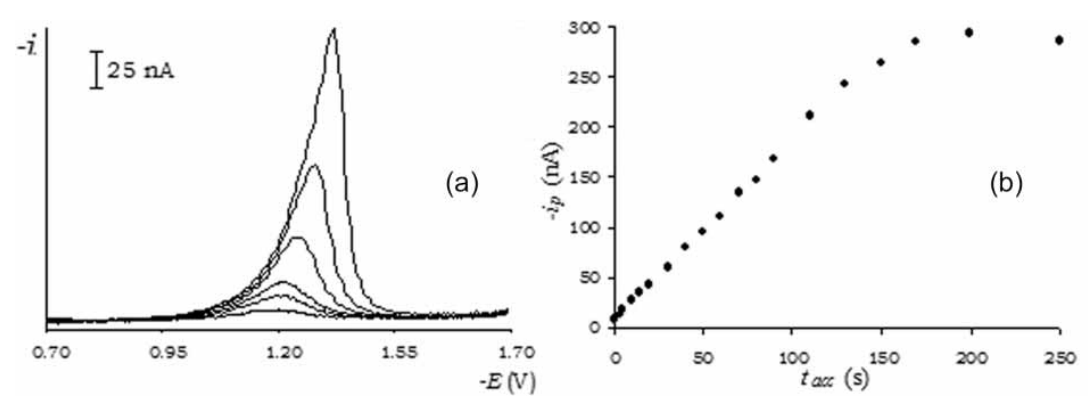

Figure 2. Square-wave adsorptive-stripping voltammetry of a $5.0 \times 10^{-7} \mathrm{~mol} \mathrm{~L}^{-1}$ CTL solution in an electrolyte of $\mathrm{pH} 12 . E_{\mathrm{acc}}=-0.8 \mathrm{~V} ; f=120 \mathrm{~Hz} ; \Delta E_{\mathrm{s}}=4 \mathrm{mV}$; $\Delta E_{\mathrm{p}}=30 \mathrm{mV}$. (a) Voltammograms for $t_{\mathrm{acc}}=0 ; 5 ; 10 ; 30 ; 60$; and $120 \mathrm{~s}$. (b) Effect of $t_{\mathrm{acc}}$ on $i_{\mathrm{p}}$.

pharmaceutical. There was no need for prior filtration of the sample because a large dilution was made and the standard addition method was used.

\section{RESULTS AND DISCUSSION}

\section{Method Development}

The electrochemical behavior of CTL was studied by SWV and SWAdSV and an analytical signal was only obtained at high $\mathrm{pH}$ values (between 10 and 12), which increased with increasing electrolyte $\mathrm{pH}$. A maximum peak current intensity $\left(i_{\mathrm{p}}\right)$, with a good repeatability, was obtained at $\mathrm{pH} 12$. At this $\mathrm{pH}, \mathrm{CTL}$ presented a reduction peak at approximately $-1.25 \mathrm{~V}$, which increased with increasing $t_{\text {acc }}$ (Figure 2a). For a $5.0 \times 10^{-7} \mathrm{~mol} \mathrm{~L}^{-1} \mathrm{CTL}$

Table 1. Characteristics of the calibration plots of CTL obtained with the proposed method

\begin{tabular}{|c|c|c|}
\hline$t_{\mathrm{acc}}(\mathrm{s})$ & 10 & 30 \\
\hline $\begin{array}{l}\text { Regression equation } \\
\quad\left(-i_{\mathrm{p}}(\mathrm{A}) ; C_{\mathrm{CTL}}\right. \\
\left.\left(\mathrm{molL}^{-1}\right)\right)\end{array}$ & $\begin{array}{l}-i_{\mathrm{p}}=(0.246 \pm 0.004) C_{\mathrm{CTL}} \\
\quad-(3.57 \pm 0.50) \times 10^{-8}\end{array}$ & $\begin{array}{l}-i_{\mathrm{p}}=(0.419 \pm 0.004) C_{\mathrm{CTL}} \\
\quad+(2.90 \pm 3.50) \times 10^{-9}\end{array}$ \\
\hline $\mathrm{n}$ & 9 & 7 \\
\hline $\begin{array}{l}\text { Linear range } \\
\qquad\left(\mathrm{mol} \mathrm{L}^{-1}\right)\end{array}$ & $3.00 \times 10^{-7}-3.00 \times 10^{-6}$ & $1.00 \times 10^{-7}-2.00 \times 10^{-6}$ \\
\hline $\begin{array}{l}\text { Correlation } \\
\text { coefficient }\end{array}$ & 0.9990 & 0.9998 \\
\hline $\operatorname{LOD}\left(\mathrm{mol} \mathrm{L}^{-1}\right)$ & $1.2 \times 10^{-7}$ & $4.7 \times 10^{-8}$ \\
\hline $\operatorname{LOQ}\left(\mathrm{mol} \mathrm{L}^{-1}\right)$ & $4.0 \times 10^{-7}$ & $1.6 \times 10^{-7}$ \\
\hline
\end{tabular}


Table 2. Results from evaluation of the precision

\begin{tabular}{lll}
\hline Parameter & $t_{\mathrm{acc}} 10 \mathrm{~s}$ & $t_{\mathrm{acc}} 30 \mathrm{~s}$ \\
\hline Repeatability (RSD \%) & $1.7(0.60)$ & $0.9(0.60)$ \\
& $1.2(1.4)$ & $1.0(1.1)$ \\
& $0.6(2.2)$ & $0.4(1.6)$ \\
Intermediate precision (RSD \%) & $2.3(0.60)$ & $1.4(0.60)$ \\
& $1.7(1.4)$ & $1.1(1.1)$ \\
& $1.1(2.2)$ & $0.6(1.6)$ \\
\hline
\end{tabular}

Concentrations, in $\mu \mathrm{mol} \mathrm{L}^{-1}$, are given in parentheses.

solution this increase is significant for up to approximately $150 \mathrm{~s}$ (Figure 2b) at an optimized $E_{\text {acc }}$ of $-0.8 \mathrm{~V}$, after which the increase of $i_{\mathrm{p}}$ levels off, possibly because of saturation coverage of the drop and/or competitive adsorption.

Several experimental parameters related to the square-wave potential scan, for example frequency $(f)$, pulse step $\left(\Delta E_{\mathrm{s}}\right)$, and pulse amplitude $\left(\Delta E_{\mathrm{p}}\right)$, were studied and optimized to obtain maximum $i_{\mathrm{p}}$ and repeatability. These parameters are interrelated and have a combined effect on the analytical signal. Different values for $f(10-2000 \mathrm{~Hz}), \Delta E_{\mathrm{s}}(1-15 \mathrm{mV})$, and $\Delta E_{\mathrm{p}}$ $(5-100 \mathrm{mV})$ were used, and led to the optimum conditions: $f=300 \mathrm{~Hz}$, $\Delta E_{\mathrm{s}}=3 \mathrm{mV}$, and $\Delta E_{\mathrm{p}}=50 \mathrm{mV}$.

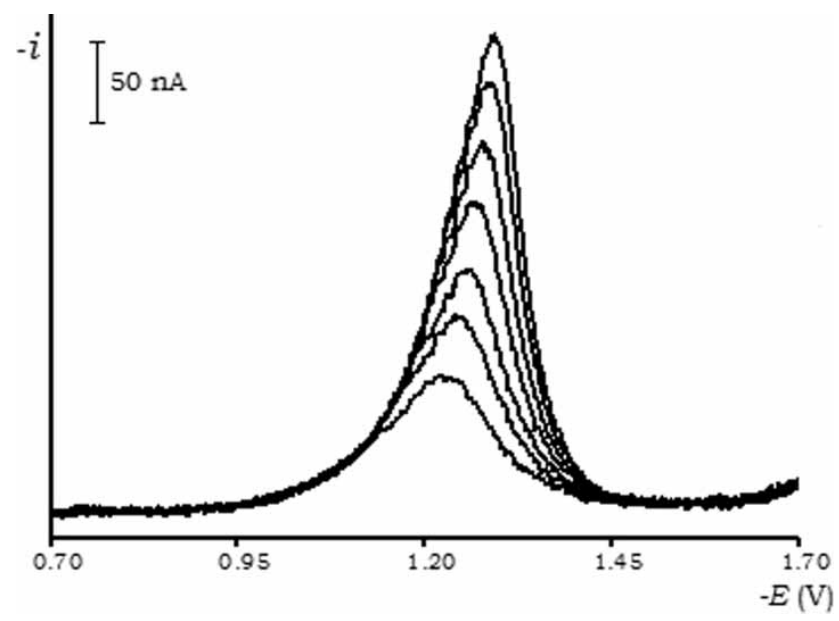

Figure 3. Typical SWAdSV analysis of CTL in a pharmaceutical using the standard addition method. Standard additions of CTL $\left(10^{-7} \mathrm{~mol} \mathrm{~L}^{-1}\right): 0$ to 6.00 (increments of 1.00). $E_{\mathrm{acc}}=-0.8 \mathrm{~V} ; t_{\mathrm{acc}}=30 \mathrm{~s} ; f=300 \mathrm{~Hz} ; \Delta E_{\mathrm{s}}=3 \mathrm{mV} ;$ and $\Delta E_{\mathrm{p}}=50 \mathrm{mV}$. 
Table 3. Results of the quantification of CTL in several pharmaceuticals

\begin{tabular}{lccc}
\hline Pharmaceutical & $C_{\mathrm{CTL}}\left(10^{-7} \mathrm{~mol} \mathrm{~L}^{-1}\right)^{a}$ & $C_{\mathrm{CTL}}(\mathrm{mg} /$ tablet $)$ & $C_{\mathrm{CTL}}(\mathrm{mg} / \text { tablet })^{b}$ \\
\hline Citalopram ratiopharm & 2.06 & 20.5 & $20.2 \pm 0.4$ \\
& 1.98 & 19.7 & \\
Cipramil (Lundbeck) & 2.05 & 20.4 & $18.8 \pm 1.8$ \\
& 4.47 & 17.9 & \\
Citalopram Sandoz & 5.24 & 20.9 & $19.7 \pm 1.1$ \\
& 4.40 & 17.6 & \\
& 4.65 & 18.4 & $19.7 \pm 1.5$ \\
Merck Citalopram & 5.16 & 20.5 & \\
& 5.04 & 20.1 & \\
Citalopram EG & 5.29 & 21.0 & \\
& 4.54 & 18.0 & \\
& 5.03 & 20.0 & \\
& 5.03 & 19.9 & \\
& 4.96 & 19.8 & \\
& 4.88 & 19.5 & \\
\hline
\end{tabular}

${ }^{a}$ Obtained in the voltammetric cell.

${ }^{b}$ Mean \pm standard deviation.

\section{Method Validation}

Table 1 lists the achieved linear range, and the LOD and LOQ values obtained in the voltammetric determination of CTL for accumulation times of $10 \mathrm{~s}$ and $30 \mathrm{~s}$.

The results from assessment of the precision, expressed as the relative standard deviation (RSD), are listed in Table 2. These results imply the method is precise and also confirm the stability of the drug solutions.

\section{Application}

In the application of the SWAdSV method to the quantification of CTL in pharmaceuticals, analyses were performed using the optimized conditions, $t_{\text {acc }}$ of $30 \mathrm{~s}$, and seven standard additions between 0 and $6.00 \times 10^{-7} \mathrm{~mol} \mathrm{~L}^{-1}$ (Figure 3). In Table 3 the results obtained are shown and it can be concluded, when compared to the labeled values $(20 \mathrm{mg}$ per tablet), that they are accurate.

\section{CONCLUSION}

Based on the electrochemical behavior of CTL, a SWAdSV analytical methodology for its quantification in pharmaceuticals was developed. The method 
was successfully applied as a good alternative to chromatographic methods for the determination of CTL in several pharmaceuticals. The developed SWAdSV method has the advantages of significantly reducing the analysis time and costs and obtaining a high sample rate.

\section{REFERENCES}

Andersen, S., Halvorsen, T.G., Pedersen-Bjergaard, S., Rasmussen, K.E., Tanum, L., and Refsum, H. 2003. Stereospecific determination of citalopram and desmethylcitalopram by capillary electrophoresis and liquid-phase microextraction. J. Pharm. Biomed. Anal., 33: 263-273.

Barros, A.A., Rodrigues, J.A., Almeida, P.J., Rodrigues, P.G., and Fogg, A.G. 1999. Voltammetry of compounds confined at the hanging mercury drop electrode surface. Anal. Chim. Acta, 385: 315-323.

Berzas, J.J., Guiberteau, C., Contento, A.M., and Rodriguez, V. 2002. Sensitive and rapid high performance liquid chromatographic method for simultaneous determination of antidepressants in pharmaceutical formulations. Chromatographia, 56: $545-551$.

Berzas, J.J., Guiberteau, C., Villasenor, M.J., and Rodriguez, V. 2004. Development of a capillary gas chromatographic procedure. Anal. Chim. Acta, 519: 219-230.

Buzinkaiova, T. and Polonsky, J. 2000. Determination of four selective serotonin reuptake inhibitors by capillary isotachophoresis. Electrophoresis, 21: 2839-2841.

Duverneuil, C., de la Grandmaison, G.L., de Mazancourt, P., and Alvarez, J.C. 2003. A high-performance liquid chromatography method with photodiode-array UV detection for therapeutic drug monitoring of the nontricyclic antidepressant drugs. Ther. Drug Monit., 25: 565-573.

Eap, C.B., Bouchoux, G., Amey, M., Cochard, N., Savary, L., and Baumann, P. 1998. Simultaneous determination of human plasma levels of citalopram, paroxetine, sertraline, and their metabolites by gas chromatography mass spectrometry. J. Chromatogr. Sci., 36: 365-371.

Fernández, C.M. and Martin, V.C. 1977. Preparation d'un tampon universel de force ionique 0,3 M. Talanta, 24: 747-748.

Flores, J.R., Nevado, J.J.B., Salcedo, A.M.C., and Diaz, M.P.C. 2004. Development of a capillary zone electrophoretic method to determine six antidepressants in their pharmaceutical preparations. Experimental design for evaluating the ruggedness of method. J. Sep. Sci., 27: 33-40.

Frahnert, C., Rao, M.L., and Grasmader, K. 2003. Analysis of eighteen antidepressants, four atypical antipsychotics and active metabolites in serum by liquid chromatography: a simple tool for therapeutic drug monitoring. J. Chromatogr. B, 794: 35-47.

Gutteck, U. and Rentsch, K.M. 2003. Therapeutic drug monitoring of 13 antidepressant and five neuroleptic drugs in serum with liquid chromatography-electrospray ionization mass spectrometry. Clin. Chem. Lab. Med., 41: 1571-1579.

Kollroser, M. and Schober, C. 2003. An on-line solid phase extraction-Liquid chromatography-Tandem mass spectrometry method for the analysis of citalopram, fluvoxamine, and paroxetine in human plasma. Chromatographia, 57: 133-138.

Labat, L., Deveaux, M., Dallet, P., and Dubost, J.P. 2002. Separation of new antidepressants and their metabolites by micellar electrokinetic capillary chromatography. J. Chromatogr. B, 773: 17-23. 
Lacassie, E., Gaulier, J.M., Marquet, P., Rabatel, J.F., and Lachatre, G. 2000. Methods for the determination of seven selective serotonin reuptake inhibitors and three active metabolites in human serum using high-performance liquid chromatography and gas chromatography. J. Chromatogr. B, 742: 229-238.

Macek, J., Ptacek, P., and Klima, J. 2001. Rapid determination of citalopram in human plasma by high-performance liquid chromatography. J. Chromatogr. B, 755: 279-285.

Mandrioli, R., Fanali, S., Pucci, V., and Raggi, M.A. 2003. Enantiomeric separation of citalopram and its metabolites by capillary electrophoresis. Electrophoresis, 24: $2608-2616$

Martinez, M.A., de la Torre, C.S., and Almarza, E. 2004. A comparative solid-phase extraction study for the simultaneous determination of fluvoxamine, mianserin, doxepin, citalopram, paroxetine, and etoperidone in whole blood by capillary gasliquid chromatography with nitrogen-phosphorus detection. J. Anal. Toxicol., 28: $174-180$.

Meng, Q.H. and Gauthier, D. 2005. Simultaneous analysis of citalopram and desmethylcitalopram by liquid chromatography with fluorescence detection after solid-phase extraction. Clin. Biochem., 38: 282-285.

Miller, J.N. and Miller, J.C. 2000. Statistics and Chemometrics for Analytical Chemistry, 4th ed.; Prentice Hall: London.

Misztal, G. and Skibinski, R. 2001. Chromatographic analysis of new antidepressant drugs by normal- and reversed-phase TLC. JPC-J. Planar Chromatogr.-Mod. TLC, 14: 300-304.

Pedersen-Bjergaard, S. and Halvorsen, T.G. 2000. Analysis of pharmaceuticals by microemulsion electrokinetic chromatography in a suppressed electroosmotic flow environment. Chromatographia, 52: 593-598.

Pistos, C., Panderi, I., and Atta-Politou, J. 2004. Liquid chromatography-positive ion electrospray mass spectrometry method for the quantification of citalopram in human plasma. J. Chromatogr. B, 810: 235-244.

Raggi, M.A., Pucci, V., Mandrioli, R., Sabbioni, C., and Fanali, S. 2003. Determination of recent antidepressant citalopram in human plasma by liquid chromatographyfluorescence detection. Chromatographia, 57: 273-278.

Sagar, G.V. 2004. Spectrophotometric determination of citalopram in pharmaceutical formulations. Asian J. Chem., 16: 1928-1930.

Skibinski, R. and Misztal, G. 2005. Determination of citalopram in tablets by HPLC, densitometric HPTLC, and videodensitometric HPTLC Methods. J. Liq. Chromatogr. Relat. Technol., 28: 313-324.

The United States Pharmacopoeia, 2000. The National Formulary, USP 24, NF 19. USP Convention, 12601, Rockville, MD.

Tournel, G., Houdret, N., Hedouin, V., Deveaux, M., Gosset, D., and Lhermitte, M. 2001. High-performance liquid chromatographic method to screen and quantitate seven selective serotonin reuptake inhibitors in human serum. J. Chromatogr. B, 761: $147-158$.

Wang, J. 1985. Stripping Analysis: Principles, Instrumentation and Applications; VCH Publishers: Deerfield Beach, FL, USA.

Waschgler, R., Hubmann, M.R., Conca, A., Moll, W., and Konig, P. 2002. Simultaneous quantification of citalopram, clozapine, fluoxetine, norfluoxetine, maprotiline, desmethylmaprotiline and trazodone in human serum by HPLC analysis. Int. J. Clin. Pharmacol. Ther., 40: 554-559. 